\title{
The Stability of the Red Reflex Produced by Different Surgical Ophthalmic Microscopes
}

\author{
Lawrence Woodard
}

Received: June 17, 2021 / Accepted: June 17, 2021 / Published online: July 13, 2021

(C) The Author(s) 2021

\section{ABSTRACT}

The red reflex is produced when coaxial light from the retina is reflected from patient to observer, and acts as an important tool in ophthalmic surgery owing to its application in screening various ocular abnormalities associated with the cornea and iris. Visualization of these intraocular structures could improve surgeons' ability to perform ophthalmic procedures safely. The aim of this podcast, featuring Dr. Laurence Woodard (Medical Director of Omni Eye Services, Atlanta), is to highlight the clinical utility of red reflex stability and intensity provided by nearly collimated and focused beam microscope illumination systems used in ophthalmic surgery. Quantifying red reflex intensity can be challenging due to its subjective nature. Other factors such as phacoemulsification and individual characteristics of the eye, such as pupil size or iris pigment, may affect red reflex intensity. Red reflex stability and intensity may also be altered during the procedure because of excessive eye movement, lack of centering, or if the eye is not perpendicular to the light beam. In addition,

Supplementary Information The online version contains supplementary material available at https:// doi.org/10.1007/s40123-021-00367-w.

L. Woodard $(\square)$

Omni Eye Services, Atlanta, GA, USA

e-mail: LWoodard@OmniEyeAtlanta.com differences in nearly collimated and focused illumination systems may affect surgeon fatigue and surgery success. The intensity of the red reflex dictates surgeons' ability to maintain adequate visualization during surgery as well as identify ocular abnormalities. In conclusion, the more intense the red reflex, the more likely a surgeon will be able to maintain adequate visualization during surgery as well as identify corneal and anterior segment abnormalities. The podcast and transcript can be viewed below the abstract of the online version of the manuscript. Alternatively, the podcast can be downloaded here: https://doi.org/10.6084/m9. figshare.14779212.

Keywords: Microscope illumination system; Ophthalmology; Red reflex

\section{PODCAST TRANSCRIPT}

Hi, I'm Dr. Lawrence Woodard, Medical Director of Omni Eye Services in Atlanta. My practice is dedicated to cataract surgery and premium intraocular lens implants. We are here today to discuss the various benefits of the different microscope light systems and the attributes that separate one system from another.

The red reflex is produced by reflection of coaxial light from the retina of the patient back to the observer [1]. So when viewed through a 
surgical microscope, the intensity and consistency of the red reflex may vary significantly based on the optical qualities of the different microscope systems. So not all systems are identical in their ability to produce the red reflex or in their ability to maintain the reflex throughout the procedure.

Eliciting the red reflex is considered a useful clinical tool because it helps highlight the anatomy of the ocular structures during surgery. By improving visualization of the ocular structures, the red reflex improves the ability of the surgeon to perform the procedure safely [2]. Some microscope systems may provide a red reflex, which is more stable throughout the procedure because eye movement and manipulation by the surgeon can have an impact on the quality of the red reflex [3].

Quantifying the red reflex intensity and stability is challenging, partially because it is quite subjective. Surgeons may differ in their perception of the intensity due to their preferences for the light characteristics of one scope versus another [2]. Also, the intensity varies throughout the procedure based on tissue penetration during phacoemulsification as well as the unique characteristics of each eye [2]. These characteristics include pupil size, iris pigment, retinal pigment, vitreous clarity, as well as corneal clarity. So stability of the red reflex can also be significantly altered during the procedure if the eye is not well centered or if the eye moves a lot. All of these variables create challenges when trying to quantify the red reflex.

There is value in red reflex testing as a screening tool for the detection of anterior segment abnormalities. The red reflex intensity does help identify anterior segment abnormalities associated with the cornea as well as the iris [4]. Specific corneal pathologies that will be more visible include cornea guttata, epithelial basement membrane dystrophy, corneal dryness, corneal edema, stromal dystrophies, and posterior polymorphous dystrophy.

The iris trans-illumination defects can also be recognized when there's a good red reflex. Surgeons frequently utilize direct illumination at the slit lab in the office to help identify these conditions [5]. So there are many situations when surgeons utilize the red reflex both in the clinic and in the operating room to help identify anterior segment abnormalities and to help with visualization during the procedures.

Patient eye movement can significantly affect the stability of the red reflex in three particular ways. First if the eye is not centered, the intensity of the red reflex may be diminished. Frequently during surgery, the eye may move somewhat due to the patient not looking in the direction of the light source. Secondly the eye may be torqued by the surgeon when instruments are in the eye, preventing the eye from being perpendicular to the light beam, which will significantly impact the red reflex. Thirdly if the patient tilts their head up, down, left, or right during the surgery, the eye may not be perpendicular to the light beam as well [3]. This issue is magnified with microscopes that have focused light versus collimated light.

There are factors which may affect surgeon preference of nearly collimated versus focused illumination systems. I believe nearly collimated light provides better illumination of the entire ocular surface and intraocular structures which improves contrast, thereby improving visualization as the eye moves during the procedure. Also depth of field is increased due to nearly collimated light [2], allowing the surgeon to visualize more structures without focusing up and down with the foot pedal. I believe this minimizes surgeon fatigue throughout the day and improves the chances of a successful surgical procedure.

The key takeaway messages on the value of red reflex testing and the challenges that surgeons face in quantifying the red reflex are first that the more intense the red reflex, the more likely a surgeon will be able to maintain adequate visualization during surgery, as well as identify corneal and anterior segment abnormalities. Especially in situations when the red reflex is diminished due to ocular pathology, such as dense cataracts, retinal abnormalities, small pupils, etc. A microscope that can generate a more intense red reflex may help the surgeon perform the procedure more successfully due to improved visualization.

It is difficult to quantify the red reflex intensity because there is some subjectivity involved due to surgeon preferences for light 
characteristics of one microscope versus another.

Thank you very much for your attention with this discussion on the importance of the red reflex and the value of the red reflex in assisting surgeons with visualization during surgery.

\section{ACKNOWLEDGMENTS}

Funding. Alcon provided funding for the development of this podcast commentary. The journal's Rapid Service Fee was also funded by Alcon.

Medical Writing Assistance. Editorial assistance with the preparation of the podcast commentary questions was provided by Jonathon Ackroyd, Springer Healthcare, UK. Funding for this assistance was provided by Alcon.

Authorship. Lawrence Woodard meets the International Committee of Medical Journal Editors (ICMJE) criteria for authorship for this article, takes responsibility for the integrity of the work as a whole, and has given his approval for this version to be published.

Authorship Contributions. Lawrence Woodard contributed to the commentary responses. LW reviewed the final audio transcript, gave his final approval, and is accountable for accuracy and integrity.

Disclosures. Lawrence Woodard is a consultant with Alcon.

Compliance with Ethics Guidelines. This article is based on previously conducted studies and does not contain any new studies with human participants or animals performed by the author.
Data Availability. Data sharing is not applicable to this article as no datasets were generated or analyzed during the current study.

Open Access. This article is licensed under a Creative Commons Attribution-NonCommercial 4.0 International License, which permits any non-commercial use, sharing, adaptation, distribution and reproduction in any medium or format, as long as you give appropriate credit to the original author(s) and the source, provide a link to the Creative Commons licence, and indicate if changes were made. The images or other third party material in this article are included in the article's Creative Commons licence, unless indicated otherwise in a credit line to the material. If material is not included in the article's Creative Commons licence and your intended use is not permitted by statutory regulation or exceeds the permitted use, you will need to obtain permission directly from the copyright holder. To view a copy of this licence, visit http:// creativecommons.org/licenses/by-nc/4.0/.

\section{REFERENCES}

1. McLaughlin C, Levin AV. The red reflex. Pediatr Emerg Care. 2006;22(2):137-40.

2. Cionni RJ, Pei R, Dimalanta R, Lubeck D. Evaluating red reflex and surgeon preference between nearlycollimated and focused beam microscope illumination systems. Transl Vis Sci Technol. 2015;4(4):7.

3. Chancy C, Schwiegerling J, Knight J. Comparison of the red reflex from three surgical microscopes. Invest Ophthalmol Vis Sci. 2014;55(13):328.

4. Leong SS, Tharayil JL, Thomas JJ, et al. The red reflex exam: highlighting the importance of physical exam maneuvers. J Pediatr Health Care. 2020;34(4):383-4.

5. Sun M, Ma A, Li F, et al. Sensitivity and specificity of red reflex test in newborn eye screening. J Pediatr. 2016;179:192-196.e4. 